\title{
A importância da contabilidade de competência para a informação de custos governamental*
}

\author{
José Alexandre M. Pigatto** \\ Victor Branco de Holanda*** \\ Cristiane R. Moreira**** \\ Frederico A. Carvalho*****
}

SumÁrio: 1. Introdução; 2. Pressões interna e externa por mais informações; 3. Regimes contábeis; 4. Gastos interorçamentários: custos da administração governamental; 5. Custos de transação; 6. Custos sociais; 7. Dinâmica financeira patrimonial; 8. Considerações finais.

Summary: 1. Introduction; 2. Inside and outside pressures for more information; 3. Accounting regimes; 4. Inter-budgetary expenses: government managment costs; 5. Transaction costs; 6. Social costs; 7. Patrimony financial dynamics; 8. Final remarks.

Palavras-chave: finanças públicas; contabilidade governamental; custos.

KEYWORDs: public finance; governmental accounting; costs.

A gestão financeira governamental, calcada em indicadores fiscais de curto prazo, tem sido questionada quanto à capacidade de atender aos anseios informacionais

\footnotetext{
* Artigo recebido em fev. e aceito em maio 2010.

** Professor do Departamento de Administração do Cesnors da Universidade Federal de Santa Maria (UFSM). Endereço: Av. Independência, 3751, sala 102, Caixa Postal 511- CEP 98300-000, Palmeiras das Missões, RS, Brasil. E-email: pigatto71@gmail.com.

$* * *$ Professor do Departamento de Ciências Contábeis da Universidade Federal do Rio Grande do Norte (UFRN). Endereço: Rua Alexandre Câmara, 1884 - CEP 59082-200, Natal, RN, Brasil. E-mail: victorbholanda@gmail.com.

**** Professora do Departamento de Administração do Cesnors/UFSM. Endereço: Av. Independência, 3751, sala 102, Caixa Postal 511 - CEP 98300-000, Palmeiras das Missões, RS, Brasil. E-mail: crisrmoreira@hotmail.com.

$* * * * *$ Professor do Programa de Mestrado em Ciências Contábeis da Universidade do Estado do Rio de Janeiro (Uerj). Endereço: Rua Sá Viana, 99, apto. 502 - CEP 20540-260, Rio de Janeiro, RJ, Brasil. E-mail: fdecarv@gmail.com.
} 
de diferentes stakeholders. A cidadania se realiza através da garantia dos direitos individuais, especialmente o direito à informação. Os fluxos financeiros isoladamente não representam o consumo de recursos, nem seu comprometimento no longo prazo, evidenciando ao cidadão o impacto imediato do uso de recursos públicos e pouco dizendo sobre o aumento de encargos no futuro. Um regime mais abrangente pode evidenciar uma cifra de longo prazo intergerações, contribuindo para a tomada de decisão política fiscal e operacional. Essa possibilidade suscita ajustes metodológicos na informação contábil governamental. Este artigo discute os mecanismos de pressão por melhores informações e suas diferentes expressões, apresentando um caso fictício para exemplificar parte dos argumentos teóricos.

The importance of accrual-basis accounting for government cost information Governmental finance management driven by short-term fiscal ratios has been challenged as to its capacity to meet information needs from different stakeholders. Citizenship is accomplished by ensuring individual rights. Financial flows alone do not fully represent neither consumption, nor commitment of citizens' resources in the long run. They can only show the immediate impact upon public resources use and say little about burden increasing in the future. A broader basis of accounting could disclose long-run intergenerational figures and better supports fiscal and operational policies decision making. This article discusses pressure mechanisms for better information and their manifestations. A case was prepared to illustrate some of the main arguments.

\section{Introdução}

A procura pelo desenvolvimento e pela promoção do bem comum no Brasil tem sido um problema persistente durante décadas, resistente às teorias econômicas e aos planos políticos. Uma questão intrigante e difícil de responder é: por que após tantos anos de investimento ainda não conseguimos atingir um grau razoável de desenvolvimento?

Cada época apresenta desafios governamentais diferentes. A crise dos anos 1930 caracterizou-se pela insuficiência na demanda e a mais recente, como a crise fiscal do Estado (Pereira, 1996:15). O remédio para a de 1930 foi encontrado na geração de déficits fiscais que objetivavam o pleno emprego. O paradigma keynesiano aplicado às finanças públicas partia do princípio de que "no longo prazo todos estaríamos mortos" e, portanto, o que importava era o impacto da política fiscal sobre os fluxos de caixa presentes do governo e não sobre os futuros (Kotlikoff, 1993). Nessa concepção, o déficit orçamentário consolidado (fiscal, de investimentos e da Previdência) tornou-se o marco da condução das políticas fiscais e o marco referencial da gestão financeira, in- 
clusive a patrimonial. Uma assimetria de informações entre gerações fiscais e o consequente desequilíbrio entre os ativos e os passivos podem ter conduzido o país a restrições financeiras e, por conseguinte, reduzido a capacidade de investimento público. No futuro, talvez as questões se remetam a aspectos ainda mais abrangentes do que a dimensão fiscal, tal como o da questão ambiental. Este artigo explora os conceitos e as possiblidades informacionais dos custos na evidenciação mais realista de sustentabilidade na capacidade de prestação de serviços públicos.

\section{Pressões interna e externa por mais informações}

No Brasil recente, o movimento reformista do Estado foi fortalecido com o Decreto-lei no 200, de 1967, ou a reforma desenvolvimentista. O decreto introduziu, pela primeira vez, a determinação de apuração de custos no governo. Todavia, os instrumentos necessários para tornar essa reforma de fato gerencial não foram estabelecidos (Pereira, 1996:167).

A partir da década de 1980 o mundo começou a discutir e a aderir ao movimento da nova administração pública. No final dessa mesma década, a Constituição Federal brasileira (1988) institucionalizou o princípio da eficiência (CF, 1988, art. 37). O movimento da nova administração pública propôs e modificou a participação do Estado, exigindo dele uma gestão fiscal responsável. A alteração no paradigma da função e do papel do Estado demandou um modelo diferente de informação financeira. Na Nova Zelândia, por exemplo, o movimento foi impulsionado pela reforma contábil. A Espanha experimentou tais mudanças paradigmáticas e Ruiz (2000:215) sintetizou as implicações da nova administração pública no país.

Tais características apresentam a contabilidade de custos como instrumento de apuração de resultados e de aferição da competitividade das atividades empreendidas pelo governo.

No contexto de agravamento da crise fiscal brasileira, ocorreu a promulgação da Lei Complementar no 101, no ano 2000. A lei fixou uma série de restrições sobre o gasto público no curto prazo e impôs, sem especificar, mecanismos para o "... controle de custos e avaliação dos programas financiados com recursos dos orçamentos" (LC no 101/2000, art.4, inc. I). A despeito de que esta última exigência demonstrava a preocupação com a sustentabilidade da política fiscal no longo prazo, nem a LRF, nem o Decreto-lei o 200 expressaram quais seriam os meios para apurar a informação de custo. Além disso, nesses documentos não foram consideradas algumas limitações advin- 
das principalmente do escopo do regime contábil preconizado pela lei geral de finanças, a Lei no 4.320 , de 1964.

\section{Implicações da nova administração pública na gestão financeira}

\begin{tabular}{|ll|}
\hline Características da nova administração pública & Implicações contábeis \\
\hline Foco nos resultados & Contabilidade dos custos \\
Administração fundamentada na do setor privado & Medidas de desempenho \\
Ênfase na economia e redução de custos & Orçamento \\
Descentralização & Informação comparativa \\
& Contas consolidadas \\
& Informação uniforme \\
Competitividade & Auditoria de desempenhos \\
& Informação comparativa \\
Crientação para o cidadão & Evidenciação \\
\hline
\end{tabular}

Fonte: Ruiz (2000:215, tradução nossa).

\section{Regimes contábeis}

A seguir serão analisados o regime de caixa, o regime financeiro e o regime de competência patrimonial e suas possibilidades frente à evidenciação intergeneracional dos gastos públicos, de modo a verificar o seu impacto na apuração dos custos dos serviços.

\section{Regime de caixa}

A contabilidade pelo regime de caixa reconhece somente as transações e eventos no momento do ingresso ou desembolso do dinheiro. Este regime mede o resultado financeiro global de um período a partir da diferença entre o caixa recebido e o caixa pago. 
Tradicionalmente os orçamentos governamentais e suas fixações de despesas têm sido efetivados em regime de caixa. Este é um dos fatores que conduziu à prevalência do regime de caixa na contabilidade governamental. A popularidade do regime de caixa no governo emerge da necessidade parlamentar ou de outros representantes do eleitorado, de monitorar a arrecadação ou recebimentos tributários e o seu subsequente gasto a cada ano.

(Ifac, 2000:23, tradução nossa)

Os únicos ativos reconhecidos no regime de caixa são os elementos considerados caixa ou "próximos" de caixa. São considerados caixa: saldos em dinheiro, valores em trânsito e depósitos bancários. Já os valores próximos de caixa são aplicações em investimentos de curto prazo. Os pagamentos usualmente são classificados em correntes e de capital, dependendo da vida útil do ativo recebido numa transação recíproca. Esses gastos são subdivididos ainda por funções e natureza.

A falha do regime de caixa reside no fato de não fornecer informações sobre outros ativos e passivos, nem o impacto do consumo dos ativos do governo adquiridos no passado, nem o comprometimento futuro dos ativos através da geração de passivos. Centra-se apenas no fluxo de caixa do período, ignorando outros fluxos de recursos que afetam a capacidade do governo em prestar benefícios atuais e futuros à população. Como vantagem, pode-se enumerar sua maior objetividade de informação, menos sujeita a julgamentos por parte de quem a elabora e permitindo uma compreensão mais fácil pelo legislativo, pois os conceitos de arrecadação e de desembolso são de domínio público.

\section{Regime financeiro}

O regime financeiro é um pouco mais amplo do que o regime de caixa, podendo reconhecer no seu alcance as variações de itens a pagar e receber. $\mathrm{O}$ alcance da Lei $n^{-}$4.320, no entanto, é um pouco mais restritivo. De acordo com o art. 35 da Lei no 4.320, receita é o recurso arrecadado, mesmo que não houvesse previsão para tanto. Essa arrecadação pode aumentar o passivo, reduzir o ativo ou simplesmente aumentar o saldo patrimonial.

No caso da despesa, o art. 35 determina que se reconheçam os compromissos de gastos, os empenhos (que serão futuramente gastos), como de competência financeira (ou orçamentária). Isso evidencia que o regime financeiro ou orçamentário para a despesa, em que o critério de reconhecimento é 
o empenho, é ainda mais conservador do que o regime de caixa puro. Não se considera se esses gastos são despesas, custos ou investimentos e sim se são compromissos que demandam alocação orçamentária.

No regime financeiro, a primeira falha, do ponto de vista da informação de custos, é a incapacidade de retratar os custos do consumo de ativos e oriundos da assunção de passivos, ou seja, os custos financiados por orçamentos passados (ativos) ou a serem financiados por orçamentos futuros (passivos). Além disso, ele é capaz de antecipar a redução patrimonial sem que a entidade tenha se beneficiado pelo recebimento do bem ou do material adquirido.

\section{Regime de competência (accrual basis)}

O conceito de uma contabilidade que não leve em conta a competência econômico-patrimonial resume-se a registros incompletos. A necessidade de apuração de resultados e avaliação de desempenhos conduz ao conceito de regime de competência:

Regime de competência é o regime contábil segundo o qual transações e outros eventos são reconhecidos quando ocorrem (não somente quando o caixa ou seus equivalentes são recebidos ou pagos). Portanto, as transações e eventos são registrados contabilmente e reconhecidos nas demonstrações contábeis referentes aos respectivos períodos. Os elementos reconhecidos sob o regime de competência são ativos, passivos, patrimônio líquido/ativos líquidos, receitas e despesas.

(Ifac, 2006, tradução nossa)

Em razão da relação de causa e efeito estabelecida entre despesas e receitas, os resultados das entidades com fim lucrativo exigem confrontação entre ambas. Nas entidades sem fins lucrativos, como no caso do governo, essa confrontação simplesmente representa a diferença entre os valores que se incorporaram e os que se desincorporaram do patrimônio. A aplicação do princípio em ambas constitui o momento de reconhecimento da alteração patrimonial quantitativa, embora com significados distintos.

O modelo conceitual de contabilidade mensurada pelo regime de competência econômica é representado pela equação contábil, ou seja, ativo é igual a passivo mais patrimônio líquido. Essa equação é capaz de demonstrar que estoques de recursos uma entidade detém, em uma data específica, quanto de recursos essa entidade tomou emprestado e qual é seu saldo patrimonial. 
Se esse patrimônio for capaz de representar a totalidade de ativos e passivos da entidade a valor presente, então ele representa a capacidade intertemporal de geração de benefícios ao seu detentor.

No regime de caixa, a mensuração dos eventos de um período se restringe aos ingressos e desembolsos de dinheiro em caixa. No regime de competência, por sua vez, se reconhece um leque mais amplo de valores no resultado, antes que sejam arrecadados ou pagos. No regime de competência a receita é reconhecida independentemente da sua arrecadação, possibilitando, stricto sensu, um gasto sem que a respectiva disponibilidade tenha sido realizada no caixa. Esse critério é menos conservador ou prudente do que o critério de caixa.

Os ativos contabilizados são os recursos que a entidade possui, adquiridos a partir de recursos arrecadados que foram retidos e não transferidos a terceiros como benefício, compondo o patrimônio da entidade, e que devem ser capazes de gerar benefícios econômicos presentes ou futuros e ser mensuráveis monetariamente. Assim, os ativos representam estoques de benefícios transferíveis ao proprietário ou a terceiros que detenham direitos sobre capitais emprestados ou disponibilizados à entidade (figura 1).

Figura 1

Reconhecimento intergeneracional dos gastos no patrimônio

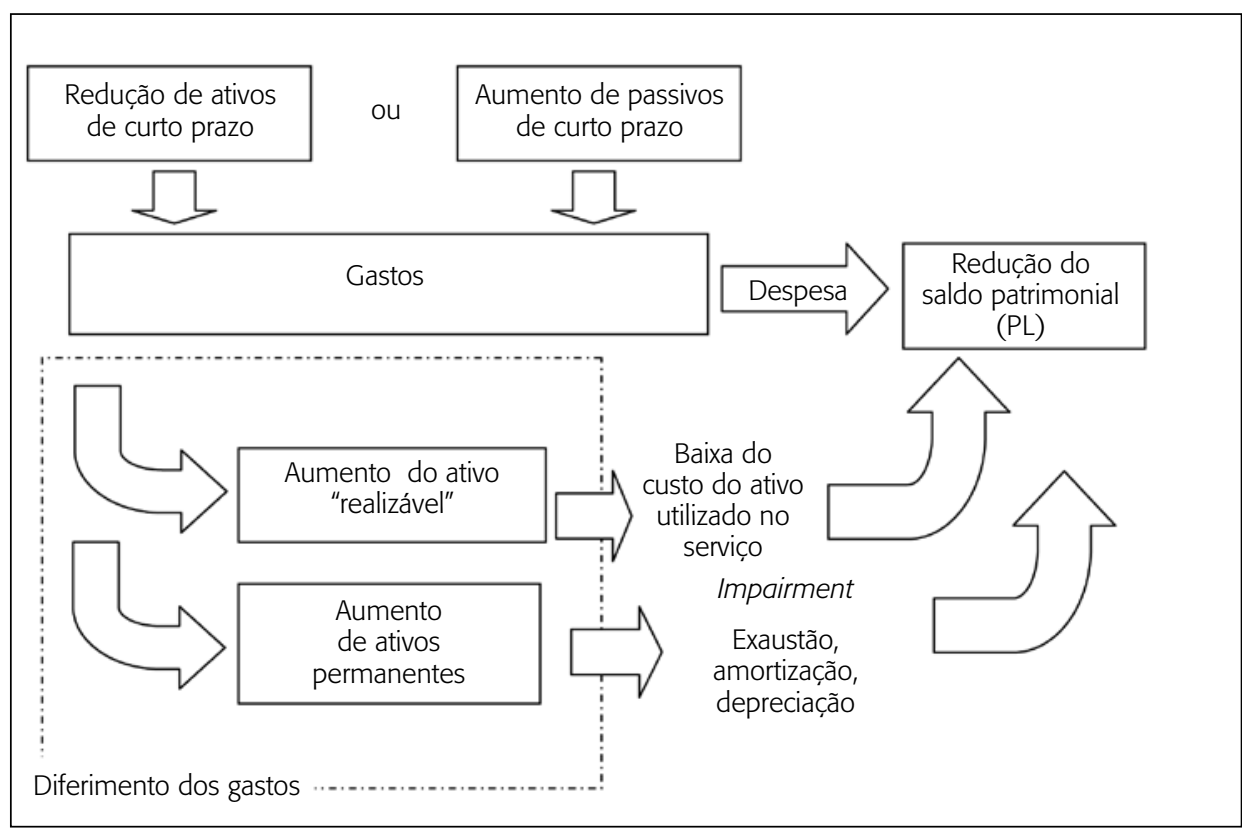

Fonte: Elaboração dos autores. 
O consumo dos ativos ocorre não só pela transferência de benefícios, mas também pela perda dessa capacidade (impairment).

Os passivos são promessas de entrega a terceiros de ativos que a entidade possui. Em outras palavras, são obrigações capazes de reduzir os benefícios econômicos da entidade no futuro pela transferência dos mesmos a terceiros (figura 2).

\section{Reconhecimento intergeneracional dos "estoques" de gastos passivos}

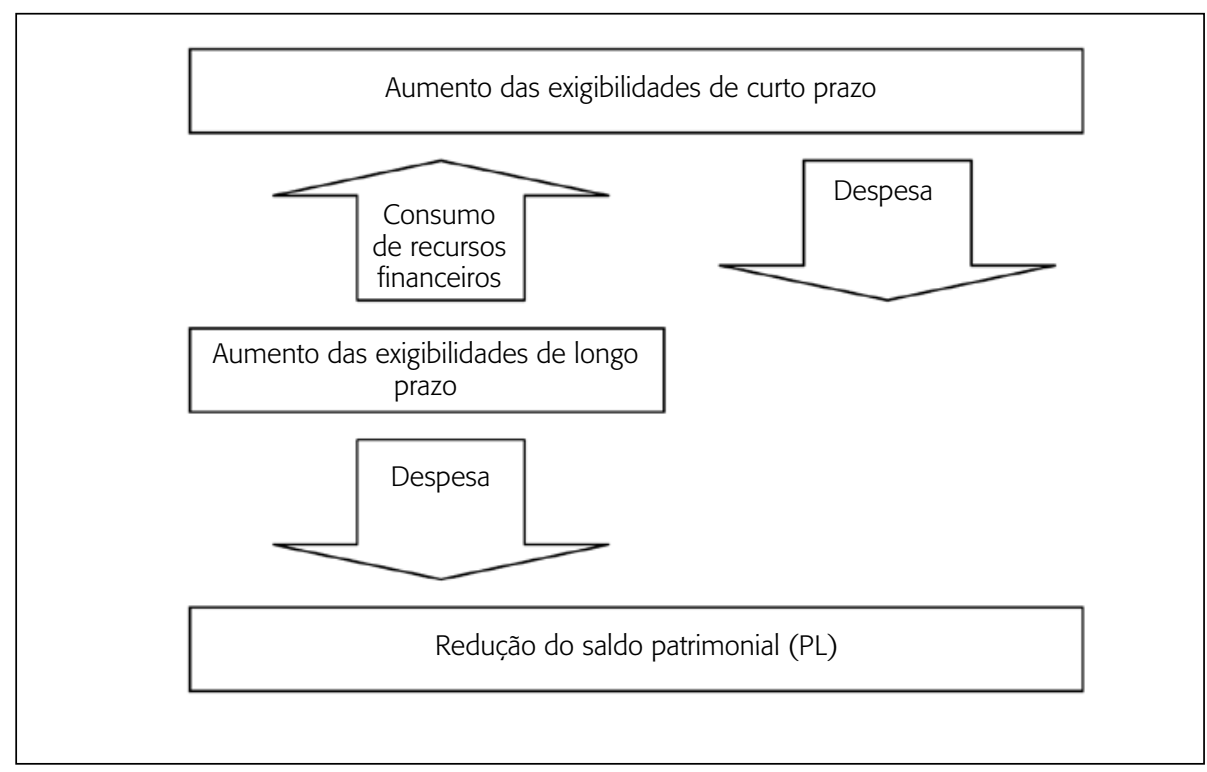

Entretanto, nem todo aumento de estoque passivo é gasto. As dívidas de longo prazo tornam-se gastos quando se aproximam de sua liquidação no caixa, pelo vencimento do principal ou do seu serviço, os juros.

Diante dessas possibilidades intertemporais de reconhecimento dos gastos incorridos na prestação dos serviços, pode-se imaginar o alcance dos fluxos em cada regime (figura 3).

As transações governamentais provocam alterações quantitativas e qualitativas no patrimônio. As variações quantitativas, no orçamento ou no patrimônio, estão associadas a períodos de tempo, identificando a competência de sua apropriação, já as qualitativas ficam restritas apenas às transações. $\mathrm{Na}$ apuração do resultado ou na avaliação do desempenho, a inclusão de recei- 
tas e de despesas depende do alcance da orientação de registro de estoques de ativos e de passivos, o que pode ter origem cultural, legal, doutrinária ou profissional.

Figura 3

Alcance da competência patrimonial

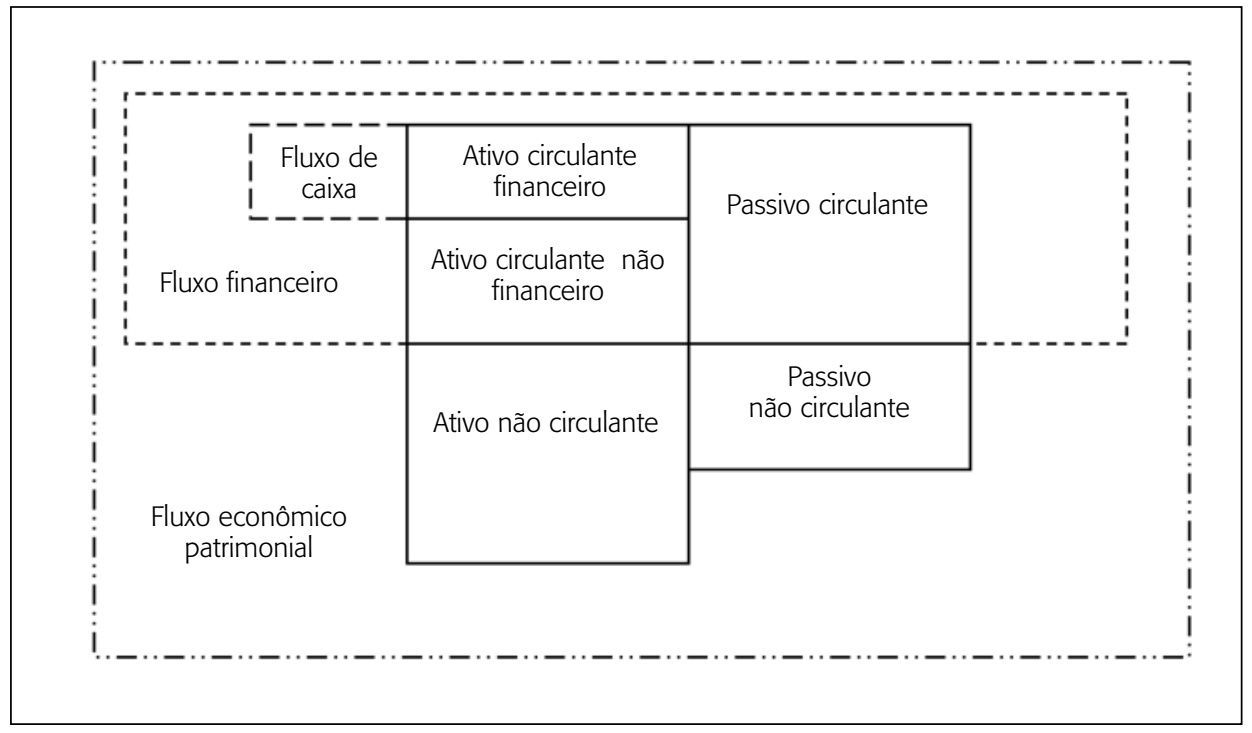

Fonte: Pigatto (2004:147).

Os diferentes estoques de ativos e passivos se inserem em uma taxonomia que pode ser diferente em se tratando de setor com fins lucrativos ou sem fins lucrativos, do tipo governamental ou social. Assim, no patrimônio os elementos ativos e passivos podem ser classificados em monetários, financeiros, circulantes, não circulantes, permanentes, de origem orçamentária ou extraorçamentária.

De acordo com Sterck, Conings e Bouckaert (2005:54), o Canadá, a Holanda, a Suécia e os Estados Unidos utilizam o regime financeiro em seu orçamento, enquanto a Austrália e o Reino Unido utilizam o regime de competência. Desses países, somente a Holanda utilizaria o regime de caixa para o patrimônio, enquanto os outros cinco países utilizariam o regime de competência. Como se observa, tais países, em sua maioria, adotam um critério misto, ou seja, um regime no orçamento e outro no patrimônio.

O Brasil também emprega um regime financeiro no orçamento e outro de competência no patrimônio, embora este último esteja em fase de expan- 
são de alcance pela adoção das normas internacionais de contabilidade para o setor público. Duas características devem ser destacadas no modelo brasileiro. A primeira é que o mesmo modelo é aplicado a todos os níveis de governo; a segunda é que a contabilidade orçamentária e a patrimonial são integradas. Esta última característica é decisiva para explicar os problemas na apuração de custos de transformação, destacados a seguir.

\section{Gastos interorçamentários: custos da administração governamental}

Uma primeira dimensão de custo representa o valor que foi ou que deve ser utilizado ou sacrificado em favor de um objetivo em particular. Trata-se do custo de transformação. Para Martins (1996:25), esse "custo é o gasto relativo ao bem ou serviço utilizado na produção de outros bens ou serviços". Em outras palavras, é o gasto apropriado no período a um objeto. Essa apropriação pode vir de estoques de ativos que foram gastos no passado ou, por exemplo, de estoques de passivos atuariais em formação, cujo gasto ocorrerá no futuro. O objeto ou portador que recebe esses custos pode ser qualquer coisa, desde que dela se deseje conhecer ou mensurar custos (Horngren, Datar e Foster, 2000:19).

No setor privado comercial os seguros, a depreciação e os salários são custos do período (despesas do exercício). Na indústria, muitos desses itens se relacionam às atividades de produção e, portanto, como custos de produção indiretos são custos dos produtos. Por outro lado, na administração governamental não há necessidade de distinção entre custos dos produtos e serviços, uma vez que o objetivo é a apuração dos custos dos serviços prestados, pressupondo-se a inexistência de estoques de serviços (Machado, 2005:110).

Dadas as peculiaridades dos regimes empregados e da integração da contabilidade do orçamento e do patrimônio, problemas surgem na apuração do custo do serviço global de uma entidade governamental. Machado (2005:110) enumera diversos problemas no caso brasileiro, entre eles: despesa orçamentária corrente, empregada na produção de ativo permanente; restos orçamentários a pagar não processados de gastos cujo valor de faturamento não se conhece no encerramento do exercício; restos orçamentários a pagar não processados de bens e serviços não recebidos; e falta de incorporação das obras públicas (bens artificiais de uso comum). Aliás, a esse respeito Petri (1987:6) já alertava que 
em termos de deficiências da Contabilidade Pública, a principal relaciona-se com as distorções que provocam o surgimento de "passivos reais a descoberto" e que se originam (...) de uma imprecisão na retratação dos ativos.

Outros problemas característicos do modelo brasileiro, apontados por Machado, dizem respeito às variações passivas independentes da execução orçamentária, não registradas, tais como depreciações, sentenças judiciais desfavoráveis e passivos atuariais em formação. Esses problemas decorrem, como foi dito, do descompasso entre, de um lado, a apropriação de gastos no orçamento e no patrimônio, e de outro, daquilo que realmente deveria ser considerado no desempenho do período.

\section{Custos de transação}

Em 1960 Ronald Coase formulou um teorema econômico que contradiz a teoria de Pigou, a saber, somente os governos poderiam internalizar as externalidades por meio de impostos e subsídios (Coase, 1960:7). Coase argumentou que, se fosse considerado o custo de oportunidade em sua acepção plena, nenhum daqueles artifícios seria necessário. Em outras palavras, em uma situação em que o custo de transação fosse zero, ganhadores e perdedores privados internalizariam as externalidades por meio de uma negociação, qualquer que fosse a parte detentora do direito de propriedade. A ausência de custos de transação seria, assim, uma presunção irrealista (Coase, 1960:1) e seria um lapso lógico no pensamento econômico clássico (Williamson, 2005:3).

Essa conclusão leva a outra, ou seja, que os custos de transação são inevitáveis, decorrendo da necessidade de desenvolver padrões regulares de interação humana (North, 1990:23). Tendo em vista sua complexidade, as interações são rotuladas de instituições e, em alguns casos, poderiam não conduzir a um resultado ótimo. Os custos de transação seriam os próprios “(...) custos de funcionamento do sistema econômico" (Williamson, 1991:269, tradução nossa) e envolveriam, por exemplo, externalidades, assimetrias de informação e outros riscos, por exemplo, decorrentes de atitudes oportunistas. Embora importantes, os custos de transação são de dificil mensuração e por isso não foram incluídos no caso aqui proposto.

\section{Custos sociais}

O custo social representa o conjunto de encargos que a coletividade suporta em função de determinada atividade. Um exemplo são os custos ambientais. 
Em grande parte sua captura dependeria do registro dos recursos ambientais mas, para a macroeconomia, o problema da operacionalização do cálculo do consumo desses ativos é um problema detectado, porém não resolvido (Montoro Filho, 1992:29).

Na esfera da contabilidade governamental esbarra-se em dois fatores que interferem na captura dos ativos e passivos ambientais, bem como de suas variações. Em primeiro lugar, os ativos registrados não representam toda a riqueza sob a jurisdição de uma administração pública, portanto, uma subtração de ativos ainda que potencial somente será possível se o ativo estiver devidamente registrado. Em segundo lugar, qual o valor a ser atribuído a esse ativo? Os recursos naturais originais não possuem um custo de aquisição. Por exemplo, as florestas são consideradas pelo Código Civil brasileiro bens imóveis e de uso comum do povo. A exploração desses recursos é contabilizada na macroeconomia como produto. Os custos de obtenção desse produto não são apurados. É como se o produto fosse obtido com custo de matéria-prima zero. Assim, na esfera microeconômica, as florestas acabam tendo o tratamento de bens de uso comum e não são registradas.

\section{Dinâmica financeira patrimonial}

O caso a seguir foi idealizado para ilustrar a problemática da apuração de custos de transformação e parte de um balanço patrimonial inicial (tabela 1) de uma entidade governamental brasileira.

Tabela 1

Balanço patrimonial inicial (em reais)

\begin{tabular}{|llll|}
\hline Ativo financeiro & 10.000 & Passivo financeiro & 3.000 \\
Ativo permamente & 90.000 & Passivo permanente & 50.000 \\
& & Saldo patrimonial (PL) & 47.000 \\
\hline
\end{tabular}

As receitas orçamentárias dessa entidade governamental, no ano em curso, são o Imposto sobre a Propriedade Territorial Urbana (IPTU) e o Imposto sobre Serviços (ISS), executados conforme a tabela 2. 
Tabela 2

Receita orçamentária e execução (em reais)

\begin{tabular}{|lrcc|}
\hline Natureza da arrecadação & Previsão & Lançamento & Arrecadação \\
\hline IPTU & 100.000 & 100.000 & 97.800 \\
ISS & 52.000 & 52.000 & 50.300 \\
\hline
\end{tabular}

As despesas orçamentárias do ano em curso foram as demonstradas na tabela 3.

Tabela 3

Despesa orçamentária e execução (em reais)

\begin{tabular}{|lcccc|}
\hline Natureza do gasto & Fixação & Empenho & Liquidação & Pagamento \\
\hline Pessoal & 80.000 & 80.000 & 78.000 & 70.000 \\
Material de consumo & 30.000 & 28.000 & 25.000 & 23.000 \\
Reforma de bens móveis & 15.000 & 12.000 & 11.000 & 10.000 \\
Equipamentos & 30.000 & 28.000 & 25.000 & 22.000 \\
\hline
\end{tabular}

Para fins de simplificação, supõe-se que a depreciação do período é de $10 \%$ do total do ativo permanente, que tanto os equipamentos, quanto a reforma de bens foram executados no final do exercício e que não houve consumo de almoxarifado. Além disso, os recebíveis da dívida ativa são a diferença entre a arrecadação e o lançamento da receita.

Os fluxos possíveis de apuração estão na tabela 4.

Os pagamentos do período totalizaram R\$ 125 mil. Por outro lado, os gastos financeiros ficaram em $\mathrm{R} \$ 148$ mil, considerando-se o total de restos a pagar processados de R $\$ 9$ mil, e não processados inscritos como obrigação jurídica de R $\$ 14$ mil. Desses gastos, $\mathrm{R} \$ 25$ mil correspondem a bens que se incorporam ao almoxarifado e $\mathrm{R} \$ 25$ mil a equipamentos adquiridos e recebidos, representando variações ativas que retificam a variação financeira passiva de $\mathrm{R} \$ 148$ mil para o movimento passivo efetivo no patrimônio líquido que se deve à execução orçamentária, ou seja, $\mathrm{R} \$ 98 \mathrm{mil}$.

Entretanto, pela prática brasileira é possível reconhecer, ainda, variações patrimoniais independentes da execução orçamentária, tal como no caso da depreciação, que teria reduzido em mais $\mathrm{R} \$ 9$ mil o saldo patrimonial, elevando a variação patrimonial passiva do período para $\mathrm{R} \$ 107$ mil. A variação patrimonial passiva reconhecida no período, contudo, não corresponde ao custo dos serviços no período. O montante de $\mathrm{R} \$ 107$ mil inclui $\mathrm{R} \$ 9$ mil de 
restos a pagar não processados e $\mathrm{R} \$ 11$ mil de despesas de reformas de bens móveis, indevidamente consideradas despesa do período.

Tabela 4

Fluxos econômico-financeiros (R\$)

\begin{tabular}{|c|c|c|c|}
\hline \multirow[t]{2}{*}{ Fluxo de caixa } & Arrecadação & 148.100 & \multirow[b]{2}{*}{23.100} \\
\hline & Pagamentos & $(125.000)$ & \\
\hline \multicolumn{4}{|l|}{ Resultado (superávit) da execução orçamentária } \\
\hline Execução da receita & Arrecadação & 148.100 & \\
\hline Execução da despesa & Empenho & $(148.000)$ & 100 \\
\hline \multicolumn{4}{|l|}{ Resultado patrimonial da execução orçamentária } \\
\hline Receita orçamentária & Arrecadação & 148.100 & \\
\hline ( - ) Mutação patrimonial, variação patrimonial passiva & & $\underline{0}$ & \\
\hline$=$ Receita efetiva (que afeta o PL) & & 148.100 & \\
\hline Despesa orçamentária & Empenho & $(148.000)$ & \\
\hline ( - ) Mutação patrimonial, variação patrimonial ativa & & $\underline{50.000}$ & \\
\hline = Despesa efetiva (que afeta o PL) & & $(98.000)$ & 50.100 \\
\hline \multicolumn{4}{|l|}{ Resultado patrimonial do período } \\
\hline Resultado patrimonial da execução orçamentária & & 50.100 & \\
\hline \multicolumn{4}{|c|}{ ( + ) Variações ativas independentes da execução orçamentária: } \\
\hline Inscrição da dívida ativa & & 3.900 & \\
\hline \multicolumn{4}{|c|}{ ( - ) Variações passivas independentes da execução orçamentária } \\
\hline Depreciação & & $(9.000)$ & 45.000 \\
\hline \multicolumn{4}{|l|}{ Custo dos serviços do período: } \\
\hline Pessoal & & $(78.000)$ & \\
\hline Depreciação & & $(9.000)$ & (87.000) \\
\hline
\end{tabular}

Fonte: Elaboração dos autores.

O saldo patrimonial final de $\mathrm{R} \$ 92$ mil (tabela 5) corresponde ao saldo inicial de $\mathrm{R} \$ 47$ mil (tabela 1 ) mais o resultado patrimonial do período (tabela 4). Contudo, só deveriam ser considerados custos dos serviços o gasto com pessoal e a depreciação, de modo que, neste caso proposto, a variação patrimonial passiva "correta" ou o custo dos serviços do período, seria R\$ 20 mil menor do que foi levado ao resultado do exercício. Outro ajuste resulta- 
ria em um problema de gestão financeira. Considerada a integração entre a contabilidade orçamentária e patrimonial, o superávit financeiro do balanço patrimonial, ou seja a diferença entre o ativo e passivo financeiro, que é fonte de recursos para abertura de créditos orçamentários, ao sofrer o ajuste deixa de evidenciar a obrigação jurídica dos restos a pagar, liberando o seu recurso de cobertura de $\mathrm{R} \$ 9$ mil para novos créditos.

Tabela 5

Balanço patrimonial final e ajustado

\begin{tabular}{|lrrllr|}
\hline & Final & Ajustado & & Final & Ajustado \\
\hline Ativo financeiro & 33.100 & 33.100 & Passivo financeiro & 26.000 & 17.000 \\
Ativo permamente & 134.900 & 145.900 & Passivo permanente & 50.000 & 50.000 \\
& & & Saldo patrimonial (PL) & 92.000 & 112.000 \\
\hline
\end{tabular}

\section{Considerações finais}

Pode-se concluir que o uso do regime de caixa ou financeiro, isoladamente, distorce o valor do custo das operações governamentais, embora sua apuração seja mais objetiva. O regime financeiro, por exemplo, atribui ao período gastos de compromissos legalmente assumidos, dos quais os fornecedores não entregaram sua parte em bens e serviços e que, portanto, não deveriam ser reconhecidos como "custos do período". Essa situação ficou demonstrada no caso apresentado.

Entretanto, a ampliação do alcance contábil pelo registro de bens artificiais de uso comum, tais como obras públicas, melhoraria a representação da sustentabilidade da capacidade de prestação de serviços públicos entre gerações. O mesmo pode se dizer a respeito de passivos em formação, por exemplo, precatórios e passivos previdenciários, que representam restrições financeiras futuras com imputação de responsabilidade presente no patrimônio, além da depreciação.

Aparentemente, o alcance máximo e mais desafiador com que um sistema governamental de custos pode se deparar, além dos custos de oportunidade, é o da evidenciação de bens naturais de uso comum - as florestas, mares, rios, lagos etc. Informar aos cidadãos sobre de quanto se dispõe destes recursos por meio de um denominador monetário não é tarefa simples. Entretanto, a mensuração desses custos - tanto os de oportunidade, quanto os sociais de 
impactos ambientais — torna imperativo levar a extensão do conceito abordado no artigo até essa fronteira.

\section{Referências}

BRASIL. Lei no 4.320, de 17 de março de 1964. Estatui normas de Direito Financeiro e para elaboração e controle dos orçamentos e balanços da União, dos estados, dos municípios e do Distrito Federal.

. Constituição Federal, de 5 de outubro de 1988.

Fiscal.

. Lei Complementar no 101 , de 4 de maio de 2000. Lei de Responsabilidade

. Lei no 10.406 , de 10 de janeiro de 2002. Institui o Código Civil.

COASE, Ronald H. The problem of social cost. Journal of Law and Economics, v. 3, n. 1, p. 1-44, Oct. 1960.

HORNGREN, C.; DATAR, S.; FOSTER, G. Contabilidade de custos. 9. ed. São Paulo: LTC, 2000.

IFAC (International Federation of Accountants). Ifac Handbook 2000 - Technical pronouncements - International public sector accounting standards. New York: Ifac, 2000.

. International Public Sector Statement. Presentation of financial statements. international public sector accounting standards. New York: Ifac, Dec. 2006.

KOTLIKOFF, Laurence J. Generational accounting: knowing who pays, and when, for what we spend. Free Press, 1993. 288 p.

MACHADO, Nelson. Sistema de informação de custo. Brasília: Enap, 2005.

MARTINS, Eliseu. Contabilidade de custos. 5. ed. São Paulo: Atlas, 1996.

MONTORO FILHO, André F. Contabilidade social - uma introdução à macroeconomia. 2. ed. São Paulo: Atlas, 1992.

NORTH, Douglass C. Institutional change and economic performance. Cambridge: Cambridge University Press, 1990.

PEREIRA, Luiz Carlos Bresser. Crise econômica e reforma do estado no Brasil — para uma nova interpretação da América Latina. São Paulo: 34, 1996. 
PETRI, Nelson. Análise de resultados no setor público. 1987. Tese (Doutorado) — FEA/USP, São Paulo.

PIGATTO, José Alexandre M. Estudo comparativo dos regimes contábeis governamentais. 2004. Dissertação (Mestrado) — FEA/USP, São Paulo.

RUIZ, Amparo G. New public management and its accounting implications: some references to recent developments in Spanish local authorities. In: CAPERCHIONE, Eugenio; MUSSARI, Riccardo (Orgs.). Comparative issues in local government accounting. Norwell: Kluwer Academic, 2000.

STERCK, Miekatrien; CONINGS, Veerle; BOUCKAERT, Geert. Linking budgeting and accounting innovation - An international comparision. In: LANDE, Evelyne; SCHEID, Jean-Claude (Eds.). Accouting reform in the public sector: mimicry, fad or necessity. Poitiers: Expert Comptable Media, 2005.

WILLIAMSON, Oliver. Comparative economic organization. Administrative Science Quarterly, v. 36, n. 2, p. 269-296, June 1991.

. The economics of governance. The American Economic Review, v. 95, n. 2, p. 1-18, May 2005. 
